\title{
Synthesis and characterization of lithiated nanostructures
}

David Leopoldo Brusilovsky ${ }^{1}$, Federico Cabello ${ }^{2}$

\author{
${ }^{1}$ Instituto de Materiales de Misiones, CONICET- Universidad Nacional de Misiones, Félix de Azara 1552, Posadas, \\ Misiones, Argentina \\ e-mail: davidb@conicet.gov.ar \\ ${ }^{2}$ Facultad de Ciencias Exactas Químicas y Naturales, Universidad Nacional de Misiones, Félix de Azara 1552, Posadas, \\ Misiones, Argentina \\ e-mail: federico_cabello8@ hotmail.com
}

\begin{abstract}
Regardless of the simple accumulation of ions in the crystal insertion sites, nanomaterials offer a new storage mechanism of lithium ions $\left(\mathrm{Li}^{+}\right)$, these storage mechanisms are formed in the interfaces and inside of the nanopores. Such kinds of storage mechanisms have no effect on the structure of the electrode material. Consequently, the charge-discharge process can continue for prolonged times. Note that singular novel nanomaterials can be developed in various shapes (rods, plates, tubes, particles, etc.) and dimensions (e.g. 0D, 1D, 2D, 3D). Each of these different possibilities of shapes and dimensions offers its specific advantages and disadvantages. Therefore, a large variety of morphological structures offering increased quantity and availability of storage sites for $\mathrm{Li}^{+}$could be designed.

In this work nanoparticles of lithiated oxide of transition metals have been synthesized and characterized. The synthesis of crystalline nanostructures generally requires a heat treatment, which involves controlled synthesis conditions. The synthesis of nanoparticles was based on the non-hydrolytic sol-gel method, considering acetates as chemical precursors. This approach presents an alternative to the usual sol-gel hydrolytic routes. Non hydrolytic methods in particular lead to improved control over the homogeneity and stoichiomtry level for multiple oxides components.

The crystal structure of the nanocrystals was determined by X-ray diffraction (XRD). The morphology, the size and the composition of the particles were analyzed by using a scanning electron microscope equipped with a microprobe for energy dispersive X-ray spectroscopy.
\end{abstract}

Keywords: Lithium-ion, sol-gel, batteries.

\section{INTRODUCTION}

Nanoparticles or nanopowders as electrode materials, are an example of the rapid implementation of nanomaterials science in the application of lithium-ion battery. In fact, carbon black, a nanomaterial that has existed for several decades, has already been used in lithium-ion batteries [1-3] since its inception as an electrode, although it does not store electrical energy and simply acts as a promoter of passive conductivity to improve the power capacity.

Significant improvements of the battery performance can be realized with using nanomaterials for the design of the "active" energy storage component of the battery electrodes, these improvements should be adjudicated to the following reasons: a) shorter diffusion (lithium-ion travels from the particle's nucleus to the surface where it transfers its charge to the electrolyte) [4], b) greater electrode-electrolyte contact area [5-6] (arising from the high surface areas inherently of the nanoparticles).

Reducing the size of the electrode particles in the nanoscale regime could also substantially reduce the mechanical stresses caused in the crystalline structure by the expansion and the volumetric shrinkage during charging and discharging [7-9]. Also some processing advantages can also be achieved while working with nano-materials as lithium-ion storage electrode components. For example, most lithium-ion cathode materials are formed from precursors containing lithium and other transition metals, which are combined and then treated under a variety of heat conditions to reach the desired oxide or phosphate composition. An homogeneous thermal profile heat treatment of nanomaterial is easier to maintain throughout the material and therefore produce an homogeneous compositions without having to resort to high energy consumption processing 
methods.

Nanoparticles of transition metal lithium oxides with spinel-like crystal structure have been synthesized by various methods, including: laser ablation, hydrolytic sol-gel, spray drying, template synthesis, combustion synthesis, microemulsion, the Pechni method, solid state reaction, and the resorcinol-formaldehyde method [10-12]. Meanwhile the non hydrolitic sol-gel synthesis route [13-14], has not reported yet for lithiated oxides.

\section{MATERIALS AND METHODS}

In a typical synthesis procedure, the transition metal acetates grade ACS (NiAc2, CoAc2, MnAc2) and lithium acetate ( $\mathrm{LiAc}$ ), all stoichiometrically weighed at $20 \mathrm{mM}$, were added under vigorous stirring at room temperature to $50 \mathrm{ml}$ of benzyl alcohol. The reaction vessel was covered, and the solution was refluxed to $160^{\circ} \mathrm{C}$ for a period of seven days.

The resulting suspensions were centrifuged, and the precipitate rinsed with tetrahydrofuran and ethanol consecutively.

The material received was allowed to dry at $60^{\circ} \mathrm{C}$ for 24 hours and was exposed to a heat treatment at $350^{\circ} \mathrm{C}$ and $600^{\circ} \mathrm{C}$ for 2 hours successively.

The crystal structure was determined by means of X-ray diffraction (XRD), with a PHILIPS PW3710 equipment, radiation generated by cobalt tube, Graphite monochromator, scintillation detector, Modality: Bragg-Brentano powder $\Theta-2 \Theta$.

The particle morphology, size and composition were analyzed with a Carl Zeiss Supra 40 scanning electron microscope with dispersive energy x-ray fluorescence microprobe (EDX).

\section{RESULTS \& DISCUSSIONS}

The obtained lithiated transition metals oxides nanostructures are closely packed as indicated by scanning electronic microscopy images (SEM) as indicated in Figure 1,
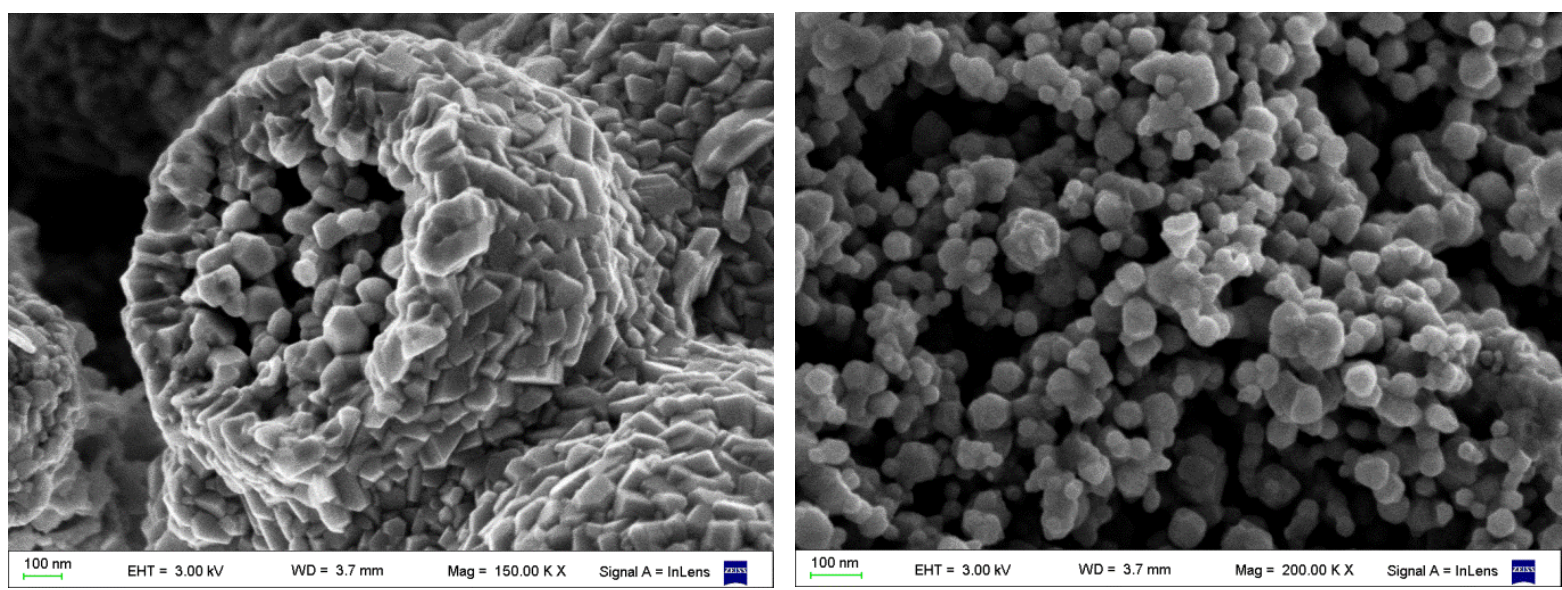

Figure 1: Scanning electronic microscopy images of lithiated transition metal oxides

The X-ray fluorescence spectrum by dispersive energy of the lithiated oxide nanoparticles confirm the presence of the Cobalt, Manganese and Nickel as components of the nanocrystalline structure (Figure 2) 


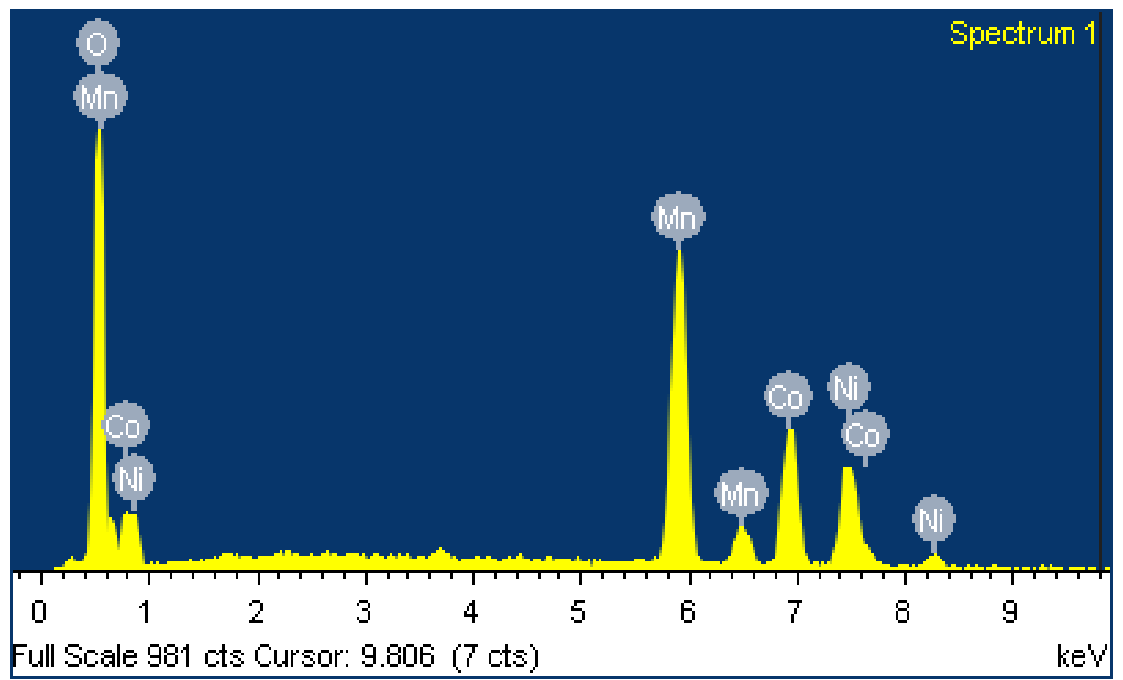

Figure 2: X-ray fluorescence spectrum by dispersive energy of lithiated Co-Ni-Mn oxide nanoparticles

The diffraction pattern is characteristic for lithium transition metal oxide spinels, resulting in a compact cubic symmetry network (space group Fd-3m, a $(\AA)=8.2785$ ) where the transition metal and lithium ions alternate octahedral sites (Figure 3) [15]

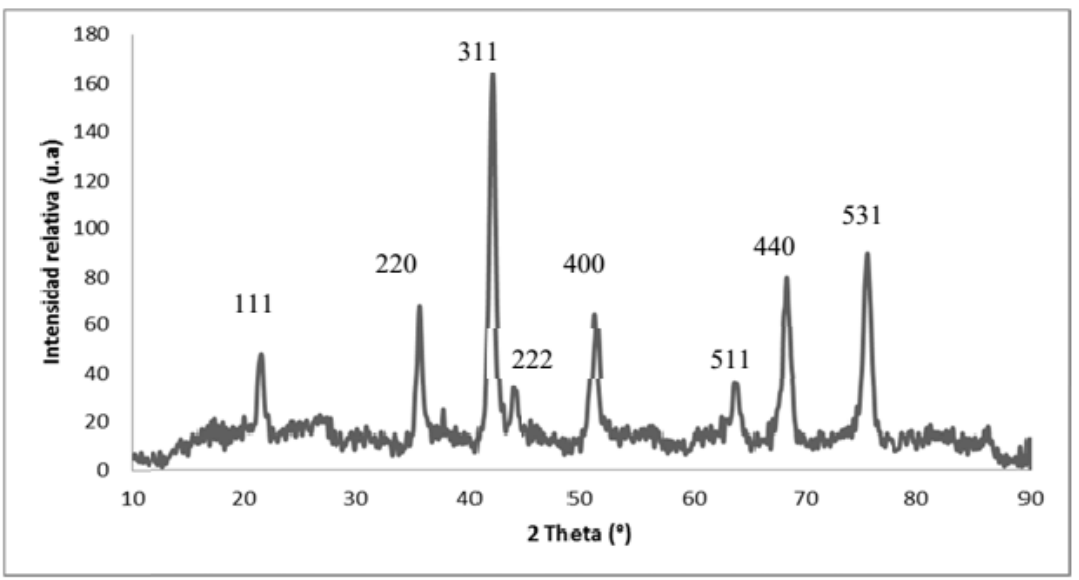

Figure 3: X-ray diffractogram of lithiated Co-Ni-Mn oxide nanoparticles

The simplicity and flexibility of the synthesis route encourage in the future to vary the metals ions ratio in order to create different compositions of nanomaterials, allowing a possible optimization in their electrochemical properties.

\section{CONCLUSIONS}

This study illustrates the successful synthesis of lithium transition metal oxide nanoparticles through a nonhydrolytic sol-gel path at low temperatures.

The reaction between acetates of transition metals and benzyl alcohol leads to forms of crystalline particles of nanometric size.

The process is simple, and supposedly makes it possible to prepare lithiated materials in gram quantities, and leads to highly crystalline nanometric materials.

\section{BIBLIOGRAPHY}

[1] GUO, Y.G., HU, J.S., WAN, L.J. "Nanostructured Materials for Electrochemical Energy Conversion and 
Storage Devices", Adv. Mater., v.20, pp.2878-2887, 2008.

[2] LIU, D., CAO, G. "Engineering nanostructured electrodes and fabrication of film electrodes for efficient lithium ion intercalation", Energy Environ. Sci., 2010, 3, 1218-1237

[3] B. SCROSATI AND J. GARCHE, "Lithium batteries: Status, prospects and future", J. Power Sources, v.195, pp.2419-2430, 2010.

[4] BALAYA, P., BHATTACHARYYA, A. J., JAMNIK, J., et al., "Nano-ionics in the context of lithium batteries", J. Power Sources, v.159, pp.171-178, 2006.

[5] LIU, Y., LIU, D., ZHANG, Q., et al., "Polymer coating of Vanadium Oxide nanowires to improve cathodic capacity in lithium batteries", Electrochim. Acta, v. 56, pp.2559-2565, 2011.

[6] BRUCE, P. G., SCROSATI, B., TARASCON, J.M. "Nanomaterials for rechargeable lithium batteries", Angew. Chem., Int. Ed., v.47, pp.2930-2946, 2008.

[7] Delmas, C., COGNACAURAdOU, H., COCCIANTElli, J. M., et al., "The $\mathrm{LixV}_{2} \mathrm{O}_{5}$ system: An overview of the structure modifications induced by the lithium intercalation", Solid State Ionics, v.69, pp.257-264, 1994.

[8] WAGEMAKER, M., BORGHOLS, W. J. H., MULDER, F. M. "Large Impact of Particle Size on Insertion Reactions. A Case for Anatase $\mathrm{Li}_{x} \mathrm{TiO}_{2}$ ”, J. Am. Chem. Soc., v.129, pp.4323-4327, 2007.

[9] TSUJI, T., TATSUYAMA, Y., TSUJI, M., et al, "Preparation of $\mathrm{LiMn}_{2} \mathrm{O}_{4}$ nanoparticles for $\mathrm{Li}$ ion secondary batteries by laser ablation in water", Mater. Lett., v.61, pp. 2062-2065, 2007.

[10] HWANG, B. J., SANTHANAM, R., LIU, D. G. "Characterization of nanoparticles of $\mathrm{LiMn}_{2} \mathrm{O}_{4}$ synthesized by citric acid sol-gel method", J. Power Sources, v.97-98, pp.443-446, 2001.

[11] CABANA, J., VALDÉS-SOLÍS, T., PALACÍN, M. R., et al., "Enhanced high rate performance of $\mathrm{LiMn}_{2} \mathrm{O}_{4}$ spinel nanoparticles synthesized by a hard-template route", Journal of Power Sources, v.166, n.2, pp.492-498, 2007.

[12] SUBRAMANIA, A., ANGAYARKANNI, N., VASUDEVAN, T. "Effect of PVA with various combustion fuels in sol-gel thermolysis process for the synthesis of $\mathrm{LiMn}_{2} \mathrm{O}_{4}$ nanoparticles for Li-ion batteries", Mater. Chem. Phys., v.102, pp.19-23, 2007.

[13] M. NIEDERBERGER, "Nonaqueous Sol-Gel Routes to Metal Oxide Nanoparticles", Acc. Chem. Res. 2007, 40, 793-800.

[14] NIEDERBERGER, M., GARNWEITNER, G. "Organic reaction pathways in the nonaqueous synthesis of metal oxide nanoparticles", Chem. Eur. J., v.12, pp.7282-7302, 2006.

[15] HOSSEINI S, NIAEI A, SALARI D.J, "Preparation and characterization of nano- and non-nanoscale $\mathrm{Co} 2 \mathrm{O} 3$ spinels obtained from different methods and study of their performance in combustion of aromatics from polluted air-A comparison with Pt/ $\gamma$-Al2O3 performance", Environ. Sci. Health A .Tox. Hazard Subst. Environ. Eng. 2012, v.47, n.12, pp. 1728-1732, 2012. 